Copyright (C) 2021 by Cherkas Global University

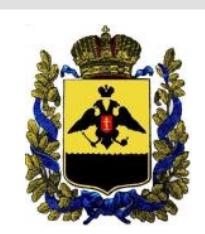

Published in the USA

Bylye Gody

Has been issued since 2006.

E-ISSN: $2310-0028$

2021. 16(4): 2026-2033

DOI: $10.13187 / \mathrm{bg} .2021 .4 .2026$

Journal homepage:

https://bg.cherkasgu.press

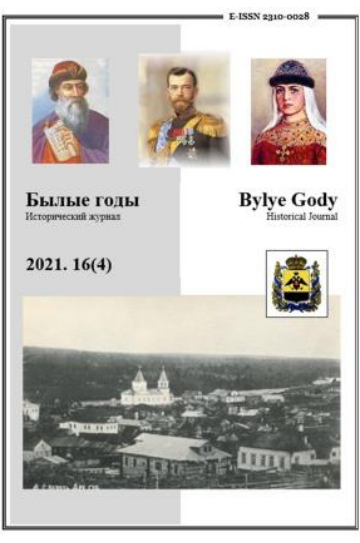

\title{
Philanthropy in the Field of Guardianship and Care of Children in the Town of Tsaritsyn of the early 20 th century
}

Irina N. Litvinova a, *, Oksana A. Karagodina a, Elena O. Danilova a

a Volgograd State University, Russian Federation

\begin{abstract}
Based on the materials of Tsaritsyn and partly his district, the specifics of the main forms and directions of charity in the Lower Volga province at the turn of the XIX-XX centuries are considered. The special role of entrepreneurs in improving the work of institutions in the areas of public care and care for orphans, as well as education and assistance to students from poor segments of the population is shown. To a certain extent, the philanthropic activities of public organizations and individuals in the field of healthcare in relation to the category of "babies", as well as rural residents in a lean year, are considered. A new source, introduced into scientific circulation, is analyzed in more detail - a report on the activities of the Tsaritsyn boys' shelter. The purpose of the work is to reveal the content of charitable practices in the field of guardianship and public education in a large district center of the Saratov province, to publish new information about the benefactor - a well-known merchant in the region A. N. Serebryakov and the orphanage opened by him. The materials of the article are necessary for researchers to develop a virtual excursion on one of the important topics - the social history of Volgograd.
\end{abstract}

Keywords: charitable practices, entrepreneurs, orphans, orphanages, poor pupils.

\section{1. Введение}

Вопросы филантропической деятельности на рубеже XIX-XX столетий, как и в начале XXI в., не теряют своей значимости для теоретиков и практиков благотворительной сферы. Актуальность темы связана с осмыслением социальной ценности опыта филантропии прошлого, ее эффективных форм и механизмов реализации в связи с происходящим реформированием современной системы социальной поддержки нуждающихся категорий населения. Более того, в обществе имеется запрос на необходимость выработки стратегии благотворительности и ее стимулирования.

B конце XIX - начале XX вв. в Царицынском уезде Саратовской губернии существовало три основных формы благотворительной деятельности: государственная, общественная и частная. Данная работа посвящена рассмотрению вопросов общественной и частной филантропии открытых форм деятельности - благотворительных организаций, попечительства в сфере образования и закрытой формы - деятельность приютов для детей-сирот.

\section{2. Материалы и методы}

Источниковую базу исследования составили документы фондов государственного архива Саратовской области (Саратов, Российская Федерация). Особый интерес представляют единицы хранения фондов ГАСО № 176 - «Саратовское губернское по делам об обществах присутствие» и № 2 - «Саратовское губернское правление», в частности дело № 9693 «Отчеты благотворительных обществ и учреждений». Привлекались также официальные справочные издания.

\footnotetext{
${ }^{*}$ Corresponding author

E-mail addresses: litvinova@volsu.ru (I.N. Litvinova), karagodina@volsu.ru (O.A. Karagodina), danilovaelena@volsu.ru (E.O. Danilova)
} 
Методологической основой исследования являются системный подход и принцип историзма, которые помогли, опираясь на опыт начала XX в., оценить значение благотворительности и роль благотворителей Царицына в системе попечительства социального призрения детей-сирот и народного образования. В работе также применялся междисциплинарный подход, который позволил охарактеризовать итоги общественной помощи детским приютам и учебным учреждениям города, а в уезде - итоги работы «Санитарно-благотворительного Общества при Александровском приемном покое» (лечебница) для отдельных категорий населения. Документальный анализ источников способствовал накоплению информации, сведений и переосмыслению практик филантропической деятельности общественных структур и частных лиц и дал основание полагать, что исторический опыт может быть отчасти применен в современном контексте.

\section{3. Обсуждение}

Одной из первых серьезных российских работ, посвященных проблемам благотворительности, является книга сенатора и писателя А.Д. Стога - попечителя Обуховской больницы (Стог, 1818). Автор рассматривает процесс становления организованной помощи и поддержки нуждающихся категорий. Все же основательные научные работы по благотворительной тематике, в которых анализируются не только практические, но и теоретические основы вопроса, появляются в конце XIX - начале XX вв. В данной связи можно отметить двухтомный труд «Благотворительная Россия» (Благотворительная, 1901). В этой монографии под редакцией П.И. Лыкошина представлен анализ истории благотворительности со времен допетровской Руси до периода правления Николая I. В частности, рассматривается деятельность учреждений ведомства императрицы Марии Федоровны и крупных филантропических обществ данной направленности, их попечителей.

Основное внимание в работах дореволюционного периода, в том числе в трудах публициста Е.Д. Максимова, акцентируется на благих делах общественно-государственных структур, находившихся под патронатом членов императорской семьи, - «Императорского Человеколюбивого Общества» Императорской канцелярии учреждений императрицы Марии (Максимов, 1903). В целом дореволюционная литература не рассматривала благотворительность с позиции крупного социального явления жизни России XIX - начала XX вв.

Отношение к благотворительности в советском обществе имело негативный характер из-за доминирующего влияния марксистской идеологии. Поэтому явлениям, относящимся к буржуазному прошлому, в том числе проблемам благотворительности и тесно связанной с ней истории делового мира, советскими учеными уделялось незначительное внимание. Например, филантропия российских предпринимателей рассматривалась односторонне, с позиции корыстных побуждений капиталистов к славе, наградам и званиям при жизни, или же заботой об их вечном поминовении (Лаверычев, 1974; Шепелев, 1977).

Качественно новый этап в освещении проблем благотворительности, как и предпринимательства, связан с научной деятельностью историка А.Н. Боханова (Боханов, 1989). Еще до официально начавшегося постсоветского периода в историографии проблемы автор смог отойти от основной догмы марксистской методологии понимания исторического процесса как постоянной и непримиримой борьбы классов, а также от пристрастного отношения к нашему объекту исследования - филантропии.

Постсоветский этап изучения истории благотворительности в начале 1990-х гг. был связан с усилением значимости социальных практик по поддержке быстро обедневших слоев населения в период так называемых либеральных реформ. В конце 1990-х - начале 2000-х гг. авторами из различных областей науки издавалось немало литературы, посвященной данной тематике. Одним из первых основополагающих трудов стал очерк историка Л.В. Бадя, в котором дано социологическое определение благотворительности, освещены традиции филантропии и выявлена ее сущность с позиции социального движения и особо значимого вида деятельности (Бадя, 1993). Социолог Э.А. Фомин рассматривает благотворительность как социокультурный феномен и как необходимый значимый общественный институт (Фомин, 1999).

Для нашей работы наибольший интерес представляют исследования регионального характера, т.к. проблема благотворительности ассоциируется сегодня и как часть истории края, а также тесно связанной с данным феноменом истории регионального предпринимательства. В этой связи отметим труды исследователей Н.К. Гуркиной и Г.Н. Ульяновой. В работе проф. Н.К. Гуркиной освещены особенности благотворительности в губерниях Европейского Севера (Архангельская, Вологодская, Мурманская области); рассмотрены система организованной общественной благотворительности в целом, а также роль в филантропии «различных социальных страт провинциального общества» и отдельных частных лиц (Гуркина, 2016). Исследователем Ульяновой Г.Н. на основе массовых первичных данных анализируются объем и динамика пожертвований, структура и мотивы благотворительности московских предпринимателей - со времени введения городского самоуправления и до начала Мировой войны (Ульянова, 1999). Из последних публикаций отметим работу Е.С. Матвеевой, А.В. Меркулова, посвященную проблеме воспитательных домов, а также значимости благотворительных обществ в развитии данных учреждений (Матвеева, 2019).

$$
-2027-
$$




\section{4. Результаты}

Содержание учебных учреждений и приютов Царицына лишь частично осуществлялось за счет средств казны, основные поступления в учреждения социального типа шли от сословных корпораций, коммерческих структур (биржевые комитеты, общества взаимного кредита) и пожертвований от частных лиц, входивших в состав попечительных советов различных организаций. Н.К. Гуркина утверждает, что лишь $25 \%$ финансирования приютских учреждений в стране происходило на государственные средства, а остальные $75 \%$ - за счет добровольных пожертвований предпринимателей и общественных структур (Гуркина, 2016: 112).

Почти все учебные заведения среднего и нижнего звена г. Царицына имели своих попечителей. Например, 6 народных училищ находились в ведении одного попечительного совета. При каждой из четырех гимназий, реальном и коммерческом училищах действовали свои советы. Как правило, помимо членов педагогического состава, в роли попечителей чаще выступали представители торговопромышленных кругов, они же являлись гласными городской думы. Известно, что филантропическая деятельность в России конца XIX - начала XX вв. была тесно связана с представителями предпринимательской среды. С 1912 г. рамки деятельности попечительных советов были значительно расширены. Они получили право заниматься не только административными, учебно-педагогическими и социально-экономическими вопросами, но и непосредственно воздействовать на сферу содержания образования, т.е. влиять на систему управления образовательными учреждениями. Еще большую значимость приобрела деятельность попечителей на региональном уровне (Закон..., 1912).

В компетенцию земств также входили дела благотворительные, строительство церквей, школ, попечение о народном здравии, образовании и т.д. Земские, сословные, сельские общества и частные лица в форме денежных пожертвований и отчислений от коммерческих организаций участвовали в развитии сети учреждений народного образования. Подобным образом в 1904 г. в посаде Дубовка было открыто высшее начальное училище и при нем ремесленный (слесарно-токарный) класс, в 1906 г. - частная женская гимназия и реальное училище.

В начале XX ст. в отдельных волостях уезда стали активно действовать общественные структуры, в задачи которых входила материальная поддержка нуждающихся или оказание медицинской помощи. Так, в Александровской волости Царицынского уезда с 1906 г. действовало «Санитарно-благотворительное Общество при Александровском приемном покое», созданное по инициативе уездного земства. Согласно Уставу, целью Общества являлось улучшение санитарного положения в Александровской волости, оказание помощи нуждающимся больным и их семействам (ГАСО. Ф. 176. ОП. 1. Д. 9. Л. 14).

В задачи данного Общества входило следующее:

- снабжение выздоравливающих одеждой, обувью, ортопедическими принадлежностями в виде бандажей, костылей, протезов, а также в крайних случаях выдачи больным денежных пособий;

- приискание для нуждающихся подходящих занятий;

- помещение дряхлых, престарелых, неспособных к труду, слепых и хронически-больных в богадельни, приюты и специальные лечебницы;

- устройство приюта «Ясли» для детей тех больных, которые, поступая в больницу, не могли оставить их на чье-либо попечение;

- попечение семейств, которые терпят нужду вследствие заболевания кого-либо из членов семьи;

- забота о школьной санитарии: устройство завтраков в школе и прочее (ГАСО. Ф. 176. Оп. 1. Д. 9. Л. 14).

Совет Общества рассматривал различные вопросы: о выдаче денежных пособий лицам, лечащимся на дому (в т.ч. роженицам); пособий хирургическим больным на поездку в Царицын для дальнейшего лечения. Решались и вопросы непосредственно благотворительного содержания оказание помощи лицам, «впавшим в нищету» и пострадавшим от неурожая. Например, в неурожайный 1906 г. Общество оказало помощь 48 больным в виде денежного пособия, в сумме 80 руб. 12 коп., на покупку продуктов (молока, мяса), одежды и др. (ГАСО. Ф. 176. Оп. 1. Д. 9. Л. 27).

В 1907 г. данная организация оказала помощь нуждающимся семьям, пострадавшим от неурожая предыдущего года. Из отчета Общества следует, что поддержку на сумму 99 руб. получили более 150 чел. (ГАСО. Ф. 176. Оп. 1. Д. 9. Л. 14). Траты невеликие, но спасали семьи от голода.

Помимо прочих расходов, в 1907 г. советом Санитарно-благотворительного общества было принято решение об оказании материальной помощи Александровской волостной богадельне, где призревалось 12 престарелых человек обоего пола. Следовательно, в Александровской волости имелся приют для престарелых крестьян, и данный факт ранее был неизвестен исследователям социальной истории края.

В целом решение вопросов здравоохранения в уезде и центре нельзя было назвать благополучным. Постоянные вспышки холеры, чумы в волжских городах требовали особого внимания к развитию медицины в городе и уезде. На время эпидемий действовали холерные бараки и врачебная комиссия, работа которых имела государственно-общественный характер. Только в 
апреле 1905 г. в Царицыне появилась первая городская Александровская больница, при ней работали лечебница и стационар, рассчитанный на 70 коек (Литвинова, 2011: 122). До этого имелись 2 земские больницы и амбулатория. Построена Александровская больница на средства потомственного почетного гражданина К.В. Воронина и подарена городу. Константин Васильевич Воронин входил в пятерку богатейших людей Царицына, ему принадлежали трехэтажная гостиница, маслозавод, крупное поместье в районе Ельшанки (предместье Царицына). В 1914 г. в Царицыне, благодаря частным пожертвованиям, действовало уже 4 больницы и 4 амбулатории на 135 тыс. жителей (Водолагин, 1968: 113).

В городах благотворительная система развивалась по нескольким направлениям, основными группами призреваемых являлись сироты, престарелые и калеки. В период Мировой войны состав призреваемых расширился за счет вдов и беженцев. Все же первую позицию среди призреваемых в Царицыне занимали дети, а именно - категории «сироты» и «бедные ученики», помощь которым оказывалась как в открытых, так и закрытых формах филантропии. В отношении учащихся это были открытые формы, проявлявшиеся в выдаче ученикам денежных пособий, стипендий, предоставлении дешевого жилья прибывшим из волостей на учебу, оплате проезда до учреждений санаторного типа, в том числе оплате лечения и др.

Закрытая форма помощи выражалась в обустройстве и содержании детских сиротских приютов. Анализ различных источников показал, что в уездном центре к 1913 г. действовало 6 заведений такого типа и одно в посаде Дубовка. Детям оказывалась материальная поддержка общественными организациями, как правило, местными отделениями столичных структур - «Общества по призрению и попечению детей», Общества «Охраны материнства и младенчества», «Человеколюбивого общества» и др.

Программа учебных занятий в приютах соответствовала требованиям Министерства народного просвещения, т.е. была такой же, что и для городских или сельских училищ, относившихся к категории начальных учебных заведений (Начальные учебные заведения...).

Трудовой подготовке воспитанников в благотворительных учреждениях уделялось много времени и внимания. В обществе, в среде попечителей считалось, что ввиду отсутствия кровной семьи и возможности наблюдать жизненный опыт старших труд как средство воспитания детей был необычайно эффективен. В этой связи при приютах действовали не только общеобразовательные, но и сельскохозяйственные, слесарные, ремесленные школы или курсы, последние - в большинстве своем для мальчиков. Воспитанниц основательно обучали рукоделию, они шили белье для приютов, как, например, в Приюте для девочек под покровительством купцов Губановых - Якова Васильевича и его супруги Анны Ивановны. Это учреждение действовало при Покровском храме.

Трудовые навыки детей впоследствии становились источником их доходов. По выпуску из приютского учреждения барышни умели шить, вышивать, вязать крючком, гладить белье и в целом вести хозяйство. Некоторые из девиц впоследствии получали места экономок, горничных по рекомендации попечителей приюта или же устраивались обычными прачками и швеями. Юноши обучались сапожному мастерству, т.е. простому ремонту обуви, также плетению корзин, снастей для рыбной ловли, особо ценились навыки в плотницком и столярном деле. Воспитанники, отличившиеся в обучении арифметике, имели шансы на получение рекомендации для найма в качестве продавцов или младших приказчиков в магазинах и на складах продукции компаний.

До начала XX в. в городе действовал лишь один приют для младенцев-девочек, в отличие от трех богаделен для призреваемых стариков. В 1908 г. открылся городской приют «Ясли для подкидышей», которым заведовала акушерка Астахова. В начале своей деятельности «Ясли» располагались при городском родильном приюте, но в 1910 г. были переведены в отдельное помещение. Здание было построено на средства частных лиц и специально образованного для данной цели Общества, включая сумму, выделенную по решению городской думы. «Общество по постройке родильного приюта и устройству «Яслей» для подкидышей в г. Царицыне» было создано в 1906 г. Согласно уставу, его целью было, «чтобы младенцы обретали первый приют и нужный уход» (ГАСО. Ф. 176. Оп. 1. Д. 50. Л. 4).

Еще раньше, в 1902 г., в Царицыне стал действовать приют для мальчиков, в котором призревалось 40 детей под председательством попечительного совета - Григория Нестеровича Серебрякова. По сведениям «Царицынского вестника», почетный гражданин города Г.Н. Серебряков председательствовал в совете до осени 1915 г. (Царицынский вестник, 1916). Помимо учебной программы, дети здесь осваивали сапожное и малярное ремесла.

В 1904 г. открылся еще один приют для мальчиков по инициативе попечителя Александра Нестеровича Серебрякова - брата Г.Н. Серебрякова.

В процессе исследования материалов Саратовского государственного архива выявлен новый документальный источник, содержащий сведения о работе этого приюта - «Отчет о состоянии Царицынского Приюта для мальчиков за 1907 г.» (ГАСО. Ф. 2. ОП. 1. Д. 9693. Л. 76-80). Отчет составлен в форме доклада, зачитан на собрании совета попечителей приюта, а впоследствии опубликован отдельным документом для городской думы. 
В докладе председатель попечительного совета А.Н. Серебряков отмечает, что помещение приюта рассчитано на пребывание 50 сирот, но из-за недостатка средств в учреждении в отчетном году призревалось только 37-40 детей. По мнению докладчика, такое положение связано с равнодушием сограждан. Затем попечитель обращается к состоятельным жителям Царицына с призывом быть более отзывчивыми к чужой беде и содействовать воспитанию сирот, ведь «им жить в нашем городе, за ними будущее, прогресс, а значит, и будущее нашего общества» (ГАСО. Ф. 2. Оп. 1. Д. 9693. Л. 76).

Далее докладчик рассуждает о главных трудностях, связанных с нехваткой средств на содержание учреждения, однако, основывает свою речь на принципах христианства - всеобей любви к человечеству. Оратор отмечал: «...Верю в то, что заветы Христа живы и сегодня в обществе, и не заглохли заповеди любви и милосердия. Пусть это выражается не столь ярко как у первых христиан, но малой искоркой они тлеют в душе каждого христианина». Вывод докладчика: он верит, что и царицынское общество не оставит без своего внимания и помощи призреваемых воспитанников и будет оказывать посильную помощь приюту (ГАСО. Ф. 2. Оп. 1. Д. 9693. Л. 77).

Вероятно, выступление оратора было ярким и эмоциональным, полагаем, это слова человека неравнодушного, отзывчивого, искренне стремящегося улучшить жизнь детей, лишившихся родительского крова. Сведения источника дают возможность понять, что многие представители царицынского общества «не оставляли без внимания нужды воспитанников». Список состава попечительного совета приюта для мальчиков был весьма внушительным. Всего в нем значится 30 фамилий пожизненных членов и 33 - действительных членов, среди которых известные предприниматели Царицына: Мишнин, Воронины, Губанов, Кленов, Серебряковы, Репниковы, Щетинкин, Горбунов, Кожевников, Бондаренко, Сивякова, Рысины, Таппер и др.

Документ содержит благодарности членов совета в адрес некоторых горожан за оказанную помощь приюту как личным участием в виде услуг и труда, так и материалами, продуктами, деньгами. Например, за участие в судьбе сирот отмечены земский врач Л.Б. Шапиро, который всегда проявлял внимание к приютским детям в случае их заболевания, также провизор П.А. Забелло, бесплатно отпускавший лекарства из собственной аптеки для воспитанников (ГАСО. Ф. 2. Оп. 1. Д. 9693. Л. 79). Согласно источнику, известные благотворители Ю.Д. Репникова и А.А. Репников бесплатно снабжали приют тканью для одежды призреваемых мальчиков в течение 5 лет его существования.

Главной задачей основателей и попечителей подобных учреждений было изыскание денежных средств на их содержание. Так, для улучшения питания воспитанников приюта мальчиков был образован капитал имени А.Н. Серебрякова.

Согласно имеющимся сведениям, А.Н. Серебряков состоял во 2-й гильдии купечества и относился к успешным представителям деловой элиты Саратовской губернии. Совместно с братом он владел семейным акционерным обществом - торгово-промышленной компанией «Братья Г. и А. Серебряковы». Фирме принадлежали завод металлических изделий с основным капиталом в 2 млн руб., конфетная фабрика «Метрополь», карандашная фабрика и сеть винных магазинов (Акционерно-паевые предприятия, 1914: 240). Такими многогранными были интересы у семейной компании.

Документальный анализ архивного источника позволяет подробно рассмотреть деятельность Царицынского приюта А. Серебрякова за отчетный 1907 г., например, из 37-40 мальчиков, находившихся на полном обеспечении приюта, в школе обучались 30 чел. Остальные не учились по малолетству, а также по причине окончания курса школы и продолжению обучения в других учебных заведениях. В 1907 г. в школе приюта, помимо воспитанников, обучалось еще 20 приходящих детей, а еще 9 воспитанников окончили школьный курс полностью. Фактически приходящие дети не были полными сиротами, но весь день они проводили в приюте и получали еду и образование на бесплатной основе.

Следует обратить внимание на такие важные сведения отчета А.Н. Серебрякова, как получение четырьмя выпускниками (из 9 чел.) свидетельств на «льготу по отбыванию воинской повинности», а 5 воспитанников из 9 были пристроены на места в магазины (ГАСО. Ф. 2. Оп. 1. Д. 9693. Л. 78). Следовательно, подобным образом попечители заботились о дальнейшей судьбе выпускников приюта, устраивая их на работу.

Ранее было отмечено, что, помимо школьного курса, дети постигали различные ремесла. Например, в исследуемом учреждении для обучения детей сапожному ремеслу в штате состоял мастер-сапожник. Согласно документу, в отчетном году у сапожника обучалось 9 мальчиков. Такие меры способствовали формированию полезных бытовых навыков у воспитанников.

В 1913 г. в городе действовало 6 детских приютов, один из них - приют для мальчиков до 7 лет, основанный в том же году при Обществе охраны материнства и младенчества. Председателем попечительного совета учреждения являлся гласный думы, врач по «внутренним и детским болезням» Н.С. Розанов. В его приюте, располагавшемся в собственном доме, призревалось 25 детей. Следовательно, в довоенное время из действовавших шести приютов в городе два были организованы благотворительными обществами, четыре - частными лицами из деловых кругов. 
Представленные учреждения общественного призрения, попечительские структуры имели определенную цель своей деятельности, исходя из которой выбирались соответствующие методы и формы работы с сиротами, выделялись приоритетные направления в воспитании и образовании детей. Основой для деятельности приютских учреждений являлись христианская концепция помощи и принципы гуманизма. Следует отметить, что многие из гуманистических идей воспитания актуальны и в наши дни:

- заботиться о нравственном воспитании гражданина Отечества;

- принимать во внимание индивидуальные особенности и интересы воспитанников;

- научить воспитанника понимать и ценить прекрасное;

- обучить ремеслу (Развитие системы учреждений...).

Наряду с государственными учреждениями сферы призрения, воспитательными домами, действовала и разветвленная сеть церковно-приходских, частных, сословных учреждений для сирот.

\section{5. Заключение}

Таким образом, в Царицыне существовала разветвленная сеть учреждений для детей, лишенных попечения родителей. Однако количество приютов для сирот было недостаточным даже в мирное время. С началом войны численность осиротевших детей значительно возросла, но и количество учреждений интернатного типа в городе удвоилось, причем 4 детских приюта были организованы благотворительными комитетами беженских организаций - 2 польскими, латышским и литовским. Прибывавших в город сирот-евреев, немцев, армян национальные общины старались пристраивать в семьи.

В общей сложности филантропическая деятельность в отношении детей в Царицынском крае реализовывалась посредством организации и содержания детских приютов, работы попечительств и оплаты образования для бедных учащихся путем создания именных фондов, научнопросветительских организаций.

Часть объектов интернатного типа создавалась и финансировалась за счет государства, т.е. имела статью расходов в бюджете города или волости. Тем не менее на полноценное содержание приютов этих средств не хватало. Поэтому государственная система призрения и благотворительность существовали в смешанной форме, причем такая форма была свойственна российской благотворительности в целом. Царицынские купцы, коммерсанты, церковные общины, сословные организации и многие представители общества оказывали материальную помощь приютским заведениям, школам и училищам, в связи с чем все типы материальной помощи неимущим слоям населения Царицына, его уезда, и прежде всего детям, можно отнести к общественному призрению и частному призрению.

Миссия общественных организаций в зависимости от специфики деятельности также заключалась в реализации социальных функций, поддержке конкретных лиц (учащихся), оказании медицинской помощи нуждающимся в ней или материальной помощи детям-сиротам через приюты.

\section{6. Благодарности}

Работа выполнена при финансовой поддержке Минобрнауки России в рамках проекта № о6332020-0004 «Развитие методики виртуальной 3D реконструкции исторических объектов».

\section{Литература}

Акционерно-паевые предприятия, 1914 - Акционерно-паевые предприятия в России. М.: Изд-во В.В. Лаврова, 1914. 679 с.

Бадя, 1993 - Бадя Л.В. Благотворительность и меценатство в России: Краткий исторический очерк. М., 1993. 201 c.

Благотворительная Россия, 1901 - Благотворительная Россия. История государственной, общественной и частной благотворительности в России / Под ред. П.И. Лыкошина. Т. 1. СПб.: Изд. княгини О.Ф. Имеретинской и П.И. Лыкошина, 1901.

Боханов, 1989 - Боханов А.Н. Коллекционеры и меценаты в России. М.: Наука, 1989. 192 с.

Весь Царицын, 1911 - Весь Царицын. Справочник по гор. Царицыну и Царицынскому уезду на 1911 год. Царицын: Царицынская мысль, 1911. 113 с.

Водолагин, 1968 - Водолагин М.А. Очерки истории Волгограда 1589-1967. М.: Наука, 1968. 448 с.

ГАСО - Государственный архив Саратовской области.

Гуркина, 2016 - Гуркина Н.К. Благотворительность и меценатство в российской провинции на рубеже XIX-XX веков // Управленческое консультирование. 2016. № 11. С. 111-119.

Закон..., 1912 - Закон «О высших народных училищах» от 25 июня 1912 г. // Полное собрание законов Российской империи. Собрание 3-е. Т. 32. № 57515. СПб.: Государственная типография.

Лаверычев, 1974 - Лаверычев В.Я. Крупная буржуазия в пореформенный период. 1861-1900. М.: Мысль, 1974. 281 с. 
Литвинова, 2011 - Литвинова И.Н. Частная форма благотворительности в г. Царицыне // Вестник Волгоградского государственного университета. Серия 7 «Философия. Социология и социальные технологии». 2011. № 3 (15). С. 120-123.

Максимов, 1903 - Максимов Е.Д. Особые благотворительные ведомства и учреждения. СПб.: Государственная типография, 1903. 137 с.

Матвеева, 2019 - Матвеева Е.С., Меркулов А.В., Молоткова Е.Д. Роль благотворительных ведомств и общественных организаций дома Романовых в процессе поддержания быта детей во второй половине XIX - начале XX в. // Власть. 2019. № 2. С. 217-224.

Начальные учебные заведения... - Начальные учебные заведения при приютах и благотворительных обществах [Электронный ресурс]. URL: https://cyberlesson.ru/obrazovanie-v-rossiido-1917-goda/ (дата обращения: 02.08.2021).

Развитие системы учреждений... - Развитие системы учреждений призрения детей-сирот [Электронный ресурс] URL: https://studopedia.ru/6_91038_razvitie-sistemi-uchrezhdeniy-prizreniyadetey-sirot.html (дата обращения: 12.08.2021).

Стог, 1818 - Стог А.Д. Об общественном призрении в России. В 2-х т. СПб.: Изд. при М-ве полиции, 1818. 526 с.

Ульянова, 1999 - Ульянова Г.Н. Благотворительность московских предпринимателей. 18601914. М.: Мосгорархив, 1999. 510 с.

Фомин, 1999 - Фомин Э., Чикадзе Е. Благотворительность как социо-культурный феномен в России. СПб.: Изд-во Чернышева, 1999. 112 с.

Царицынский вестник, 1916 - Царицынский вестник. 17 января 1916 г.

Шепелев, 1977 - Шепелев Л.Е. Отмененные историей. Чины, звания и титулы в Российской империи. Ленинград, 1977. 153 с.

Litvinova et al., 2020 - Litvinova I.N., Danilova E.O., Karagodina O.A. Objects of Historical and Architectural Heritage of Volgograd: the Urban Environment of Tsaritsyn at the turn of the XIXXX centuries. // Bylye Gody. 2020. 58(4): 2598-2608.

\section{References}

Aktsionerno-paevye predpriyatiya, 1914 - Aktsionerno-paevye predpriyatiya v Rossii [Joint stock and share enterprises in Russia]. Moscow: Publishing House V.V. Lavrov, 1914. 679 p. [in Russian]

Badya, 1993 - Badya, L.V. (1993). Blagotvoritel'nost' i metsenatstvo v Rossii: Kratkii istoricheskii ocherk [Charity and philanthropy in Russia: A short historical essay]. Moscow. 201 p. [in Russian]

Blagotvoritel'naja Rossija, 1901 - Blagotvoritel'naja Rossija. Istorija gosudarstvennoj, obschestvennoj i chastnoj blagotvoritel'nosti v Rossii [Charity Russia. History of public, public and private charity in Russia]. Edited by P.I. Lykoshin. T. 1. St. Petersburg: publishing house of Princess O.F. Imeretinskaya and P.I. Lykoshin. [in Russian]

Bohanov, 1989 - Bohanov, A.N. (1989). Kollekcionery i mecenaty v Rossii [Collectors and patrons in Russia]. Moscow: Nauka. 192 p. [in Russian]

Fomin, 1999 - Fomin, E., Chikadze, E. (1999). Blagotvoritel'nost' kak sotsio-kul'turnyi fenomen v Rossii [Charity as a socio-cultural phenomenon in Russia]. St. Petersburg: Publishing House Chernyshev. 112 p. [in Russian]

GASO - Gosudarstvennyi arkhiv Saratovskoi oblasti [State archive of Saratov region].

Gurkina, 2016 - Gurkina, N.K. (2016). Blagotvoritel'nost' i metsenatstvo v rossiiskoi provintsii na rubezhe XIX-XX vekov [Charity and philanthropy in the Russian province at the turn of the XIX-XX centuries]. Upravlencheskoe konsul'tirovanie. 11: 111-119 [in Russian]

Laverychev, 1974 - Laverychev, V.Ja. (1974). Krupnaja burzhuazija v poreformennyj period. 1861-1900 [A large bourgeoisie in the reform period. 1861-1900]. Moscow: «Mysl». 281 p. [in Russian]

Litvinova, 2011 - Litvinova, I.N. (2011). Chastnaya forma blagotvoritel'nosti v g. Tsaritsyne [A private form of charity in Tsaritsyn]. Vestnik Volgogradskogo gosudarstvennogo universiteta. Seriya 7 «Filosofiya. Sotsiologiya i sotsial'nye tekhnologii». 3 (15): 120-123. [in Russian]

Litvinova et al., 2020 - Litvinova, I.N., Danilova, E.O., Karagodina, O.A. (2020). Objects of Historical and Architectural Heritage of Volgograd: the Urban Environment of Tsaritsyn at the turn of the XIX-XX centuries. Bylye Gody. Vol. 58. Is. 4. pp. 2598-2608.

Maksimov, 1903 - Maksimov, E.D. (1903). Osobye blagot About public charity in Russia About public charity in Russia About public charity in Russia voritel'nye vedomstva i uchrezhdenija [Special charitable departments and institutions]. St. Petersburg: State Printing House. 137 p. [in Russian]

Matveeva, 2019 - Matveeva, E.S., Merkulov, A.V., Molotkova, E.D. (2019). Rol' blagotvoritel'nykh vedomstv i obshchestvennykh organizatsii doma Romanovykh v protsesse podderzhaniya byta detei vo vtoroi polovine XIX - nachale XX v. [The role of charitable departments and public organizations of the Romanov house in the process of maintaining the life of children in the second half of the XIX - early XX centuries]. Power. 2: 217-224. [in Russian] 
Nachal'nye uchebnye zavedeniya... - Nachal'nye uchebnye zavedeniya pri priyutakh i blagotvoritel'nykh obshchestvakh [Primary educational institutions at shelters and charitable societies]. [Electronic resource]. URL: https://cyberlesson.ru/obrazovanie-v-rossii-do-1917-goda [in Russian].

Razvitie sistemy uchrezhdenii... - Razvitie sistemy uchrezhdenii prizreniya detei-sirot [Development of the system of institutions for the charity of orphans]. [Electronic resource]. URL: https://studopedia.ru/ 6_91038_razvitie-sistemi-uchrezhdeniy-prizreniya-detey-sirot.html [in Russian]

Shepelev, 1977 - Shepelev, L.E. (1977). Otmenennye istoriej. Chiny, zvaniya i tituly v Rossijskoj imperii [Canceled by history. Ranks, titles and titles in the Russian Empire]. Leningrad. 153 p. [in Russian]

Stog, 1818 - Stog, A.D. (1818). Ob obshchestvennom prizrenii v Rossii [About public charity in Russia]. In 2 t. St. Petersburg: publishing house under the Ministry of Police. 526 p. [in Russian]

Tsaritsynskii vestnik, 1916 - Tsaritsynskii vestnik [Tsaritsynsky Bulletin]. 17 january, 1916. [in Russian]

Ul'yanova, 1999 - Ul'yanova, G.N. (1999). Blagotvoritel'nost' moskovskikh predprinimatelei. 18601914 [Charity of Moscow entrepreneurs. 1860-1914]. Moscow: Mosgorarhiv. 510 p. [in Russian]

Ves' Tsaritsyn, 1911 - Ves' Tsaritsyn. Spravochnik po gor. Caricynu i Caricynskomu uezdu [All Tsaritsyn. Reference book on the city of Tsaritsyn and Tsaritsyn county]. Tsaritsyn: Tsaritsyn thought. 1911. 113 p. [in Russian]

Vodolagin, 1968 - Vodolagin, M.A. (1968). Ocherki istorii Volgograda 1589-1967 [Sketches of history of Volgograd 1589-1967]. Moscow: Science. 448 p. [in Russian]

Zakon..., 1912 - Zakon «O vysshikh narodnykh uchilishchakh» ot 25 iyunya 1912 g. Polnoe sobranie zakonov Rossiiskoi imperii. Sobranie 3-e [Law "On Higher Public Schools" of June 25, 1912. Complete Collection of Laws of the Russian Empire]. Issue 3rd. T. 32. Nr. 57515. St. Petersburg: State Printing House [in Russian]

\section{Филантропия в сфере призрения и попечительства детей в г. Царицыне начала XX века}

Ирина Николаевна Литвинова а, *, Оксана Александровна Карагодина а, Елена Олеговна Данилова а

а Волгоградский государственный университет, Российская Федерация

Аннотация. На материалах г. Царицына и отчасти его уезда рассматривается специфика основных форм и направлений благотворительности в нижневолжской провинции на рубеже XIX$\mathrm{XX}$ вв. Показана особая роль предпринимателей в совершенствовании работы учреждений сфер общественного призрения и попечения детей-сирот, а также образования и помощи учащимся из бедных слоев населения. В определенной степени рассмотрены филантропическая деятельность общественных организаций и частных лиц в сфере здравоохранения в отношении категории «младенцы», также сельских жителей в неурожайный год. Более подробно анализируется новый источник, вводимый в научный оборот, - отчет о деятельности приюта для мальчиков г. Царицына. Цель работы - раскрыть содержание благотворительных практик в сфере попечительства и народного образования в крупном уездном центре Саратовской губернии, опубликовать новые сведения о благотворителе - известном в крае купце А.Н. Серебрякове и открытом им приюте для сирот. Материалы статьи необходимы исследователям для разработки виртуальной экскурсии по одной из важных тем - социальной истории Волгограда.

Ключевые слова: благотворительные практики, предприниматели призрение сирот, приюты, бедные ученики.

\footnotetext{
${ }^{*}$ Корреспондирующий автор

Адреса электронной почты: litvinova@volsu.ru (И.Н. Литвинова),

karagodina@volsu.ru (О.А. Карагодина), danilovaelena@volsu.ru (Е.О. Данилова) 